Research Article

Xuemei Sun, Saihong Zhu, Hengxuan Zhu, Runze Duan, and Jin Wang*

\title{
Comparison and analyses of two thermal performance evaluation models for a public building
}

https://doi.org/10.1515/phys-2019-0089

Received Oct 31, 2019; accepted Nov 24, 2019

\begin{abstract}
Recently, investigations on building thermal inertia are mainly involved with the materials of the building envelope. Usually, other influencing factors are ignored, such as room ventilation, indoor heat storage, indoor cold source, indoor heat source and human behavior. In this paper, two models based on thermodynamics are given to evaluate building thermal performance. One is thermal mass model, and the other one is thermal reserve coefficient model. Based on thermal response testing data in a non-heating season, the thermal mass model was adopted to classify the envelope type, and the delay rules between the indoor temperature and the outdoor meteorological parameters are analyzed. In a heating season, the delay rules among the outdoor temperature, indoor temperature and supply water temperature are obtained by changing the supply water temperature. Thermal performance of the targeted building is evaluated with the thermal reserve coefficient model. For the same public building, two evaluation models tend to be consistent. These two evaluation models presented in this paper can be applied for the optimal design of buildings envelope.
\end{abstract}

Keywords: thermal response; thermal mass model; thermal reserve coefficient; thermal inertia

PACS: 81.70.Pg, 47.55.pb, 07.20.-n, 91.60.Ki

\section{Nomenclature}

$\boldsymbol{A}$ area $\left(\mathrm{m}^{2}\right)$

\footnotetext{
${ }^{\star}$ Corresponding Author: Jin Wang: School of Energy and Environmental Engineering, Hebei University of Technology, Tianjin 300401, China; Email: wjwcn00@163.com

Xuemei Sun, Saihong Zhu: School of Architecture and Art Design, Hebei University of Technology, Tianjin 300401, China

Hengxuan Zhu, Runze Duan: School of Energy and Environmental Engineering, Hebei University of Technology, Tianjin 300401, China
}

\author{
C specific heat capacity $(\mathrm{J} / \mathrm{kg} \cdot \mathrm{K})$ \\ $\boldsymbol{h}$ heat transfer coefficient $\left(\mathrm{W} / \mathrm{m}^{2} \cdot \mathrm{K}\right)$ \\ $\boldsymbol{K}$ reciprocal number of thermal mass (1/s) \\ $\boldsymbol{n}$ total number \\ Q heat source (W) \\ $\boldsymbol{T}$ time constant \\ $\boldsymbol{t}$ temperature $\left({ }^{\circ} \mathrm{C}\right)$ \\ $\boldsymbol{U}$ integrated heat transfer coefficient $\left(\mathrm{W} / \mathrm{m}^{2} \cdot \mathrm{K}\right)$ \\ $\boldsymbol{Z}$ thermal reserve coefficient
}

\section{Greek symbols}

\author{
$\beta$ limited heating coefficient \\ $\tau$ time (s)
}

\section{Subscripts}
$\boldsymbol{i}$ indoor
$j$ the jth order
o outdoor
w wind

\section{Introduction}

Recently, building industry scale has a rapid growth. Building industry investment accounts for around 30-40\% of total number in global infrastructure. After industry and agriculture, building energy consumption became the third largest fossil energy consumer as mentioned in Ref. [1]. According to the statistics in Ref. [2], residential building energy consumption occupied the second place after industry energy consumption in China. Allouhi et al. [3] pointed out that most of building energy consumption was from heating, ventilation, and air conditioning. Therefore, it is necessary to use renewable energy technologies and optimal operation schemes of energy supply 
systems for a reduction of building energy consumption. It was pointed out that the directions for the building energy savings were to optimize the building structure design and to construct the low-energy consumption buildings [4]. In addition, nanofluids have also made important contributions to energy savings in industrial applications [5].

Non-energy saving buildings occupy a larger percentage of the total building area around the world. For these buildings, large loss of cold or heat energy is caused by thermal bridges and cracks during refrigerating or heating season. Optimal design of energy supply systems and the upgrade of building envelope becomes the hot topics of the present studies.

$\mathrm{Gu}$ et al. [6] adopted several prediction methods and models to accurately forecast the medium-term heat load. These results were very useful for optimal design and operation in energy systems. Gagliano et al. [7] analyzed dynamic thermal characteristics for a lager historical building. They found that the installation of the refrigeration power was significantly reduced when the maximum cold load was delayed around 8-12 hours. Results indicated that thermal inertia and inner natural ventilation can reduce the overheating phenomenon and enhance the indoor thermal comfort. Johra et al. [8] studied effects of various factors on building thermal inertia, including materials of exterior envelope and energy storage performance of indoor furniture. They found that the structure of the envelope is the main factor, and the energy storage of the furniture can increase the building time constant and the elasticity coefficient of energy supply by $42 \%$ and $21 \%$, respectively. Stazi et al. [9] investigated influence of highperformance thermal insulation materials for the buildings in the Mediterranean region. They used a modified ventilation device to solve problems of poor indoor thermal comfort and higher refrigeration energy consumption for these measured buildings. By the improvement of the indoor ventilation, the uncomfortable level and refrigeration energy consumption decreased by $20 \%$ and $43 \%$, respectively. Based on thermal characteristics of the hollow brick wall, Sala et al. [10] compared experimental results with simulation results from a finite element analysis method. They found that the two-dimensional heat transfer model with the non-uniform structure showed the similar results to those from one-dimensional heat transfer model with uniform material, and the errors between these two models can be analyzed quantitatively. Desogus et al. [11] compared two on-site testing methods of thermal resistance of a building, and they found that the measured errors were mainly caused by the heat flux meter and manual operation in the non-destructive testing method. Aguilar et al. [12] established a transient model for ther- mal bridge phenomenon by using equivalent thermal wall method, and they showed the topological structures of two different thermal Bridges. Without a thermal bridge phenomenon, the heat flux will be underestimated by $25 \%$. Gu et al. [13] presented a hybrid control scheme in a heating system with distributed variable speed pumps. This optimal operation strategy had obvious advantage in saving electricity energy, which can greatly reduce the installed electricity power for energy supply systems. According to building thermal inertia and energy utilization efficiency, Aste et al. [14] used a parameter simulation method to calibrate structural parameters of an office building, including operating condition, initial calibration model, and climatic condition. Medjelekh et al. [15] studied effects of thermal and wet inertia for indoor comfort of stone houses in tropical areas. It was found that when the moisture absorption material of porous media was used in the part of envelop structure, the indoor temperature decreased by $1.5^{\circ} \mathrm{C}$, and the refrigeration energy saving rate increased by $31.5 \%$. Liu [16] used a dimensionless analysis method of dynamic temperature response to determine the subvalues which affected the heat storage capacity of building. Liu [17] investigated the integrated thermal inertia of residential buildings in a cold region of China.

In summary, most of these studies about thermal inertia are based on simulation analysis and thermodynamic models. However, it is difficult to establish a complex thermodynamic model and to choose a reasonable simulation software. Therefore, this article proposed two simple and effective models for analysis of building thermal performance, i.e., thermal mass model and thermal reserve coefficient model. Thermal response testing data of a public building is analyzed by using two rapid evaluation models, which can be recommended to apply in many industries.

\subsection{Research object}

The targeted building is built in 2005, and it is located in Tianjin, China. It contains five floors with a total construction area of $24,000 \mathrm{~m}^{2}$. Figure 1 presents the exterior and interior structures of the building. A typical room of this building was selected as the research object. Length, width and the height of the room size was measured as follows: $13.3 \mathrm{~m} \times 9.1 \mathrm{~m} \times 3.8 \mathrm{~m}$, and ratio of window to wall is 0.36 . Adjacent rooms have the same function and structure as the tested room, and influence of adjacent rooms on heat transfer is ignored. In order to weaken effects of human disturbance and indoor ventilation, the test is conducted with two periods: the first stage was from 0:00 am on Oct 1th to 


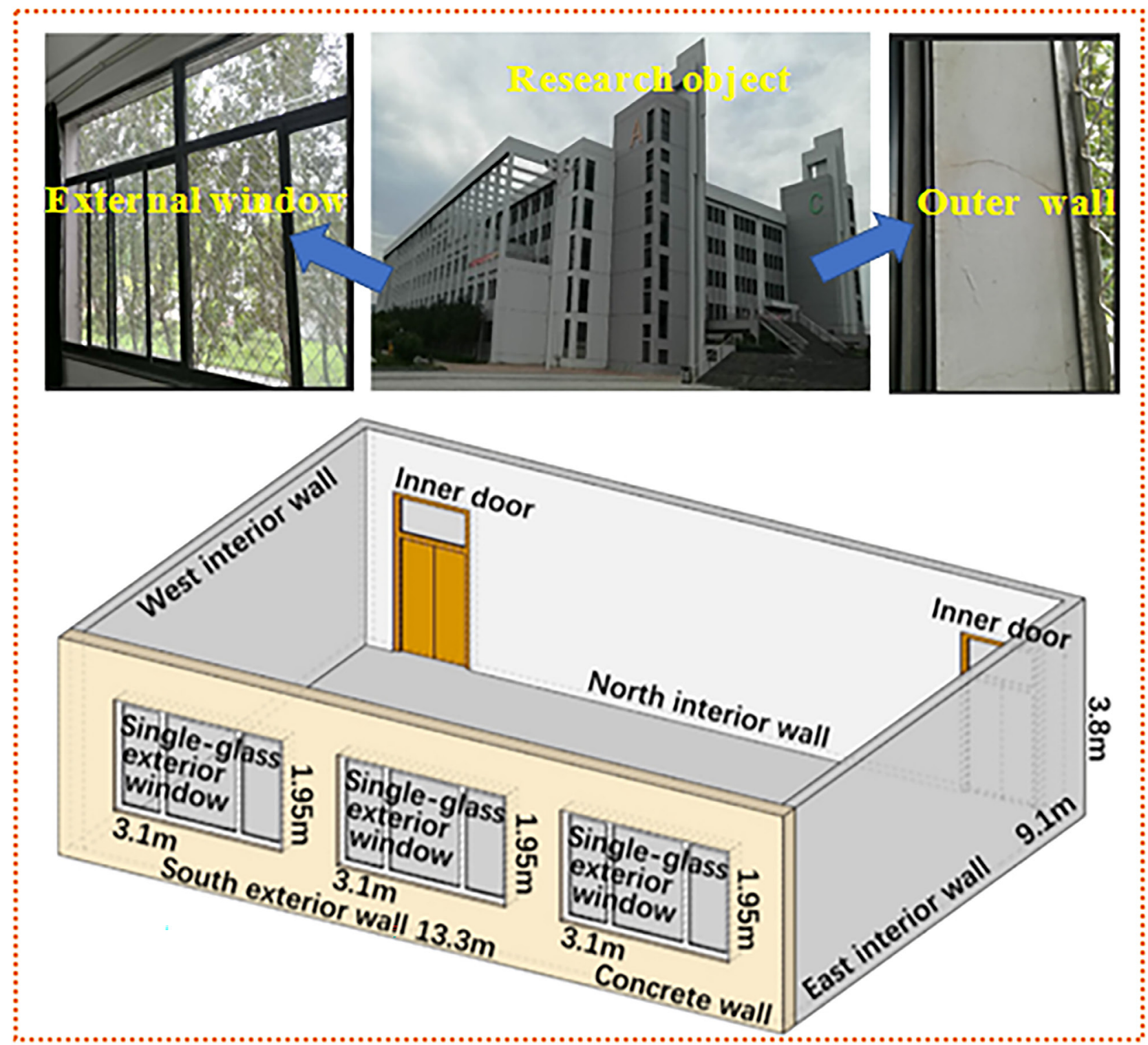

Figure 1: Targeted building and typical room

23:50 pm on Oct 5th, and the second stage was from 15:00 pm on Dec 11th to 12:00 am on Dec 12th, 2018.

A gas boiler as the heat source was used for the heat supply system, and the heat source was indirectly connected with the targeted building by a water-water plate heat exchanger. The schematic of the energy supply system was shown in Figure 2.

Some devices of this experimental system are shown in Figure 3. The energy-saving control device in each thermal entrance of the targeted building is used for hydraulic control and temperature adjustment of return water. A wireless temperature monitoring device is installed in the test room as shown in Figure 3 (b), and the indoor temperature is measured every 10 minutes. For the targeted building, the indoor temperature will decrease to save the heat energy during the night. In order to avoid freezing, the room temperature is set with a low limit value, and the electric control valve is automatically adjusted according to the set point of the room temperature. Figure 3 (c) presents a weather station which measures and transmits information of outdoor temperature, wind speed and solar radiation every one minute. As shown in Figure 3 (d), the differential scanning calorimeter is used to measure the specific heat capacity of the outer wall materials. Table 1 shows the tested parameters and specifications of the measurement devices.

The outer wall of the test room is made up of composited materials, including internal plastering, concrete, 


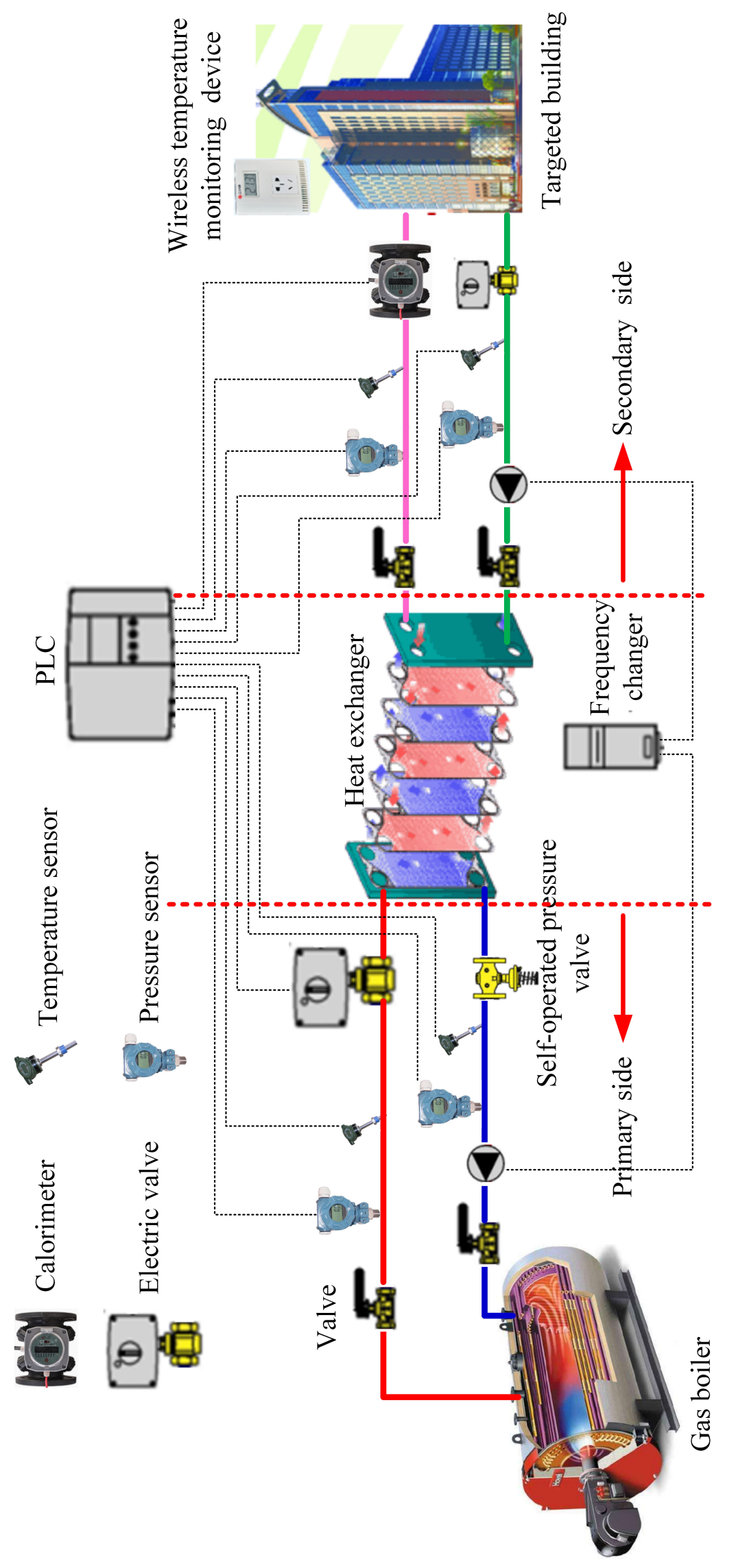



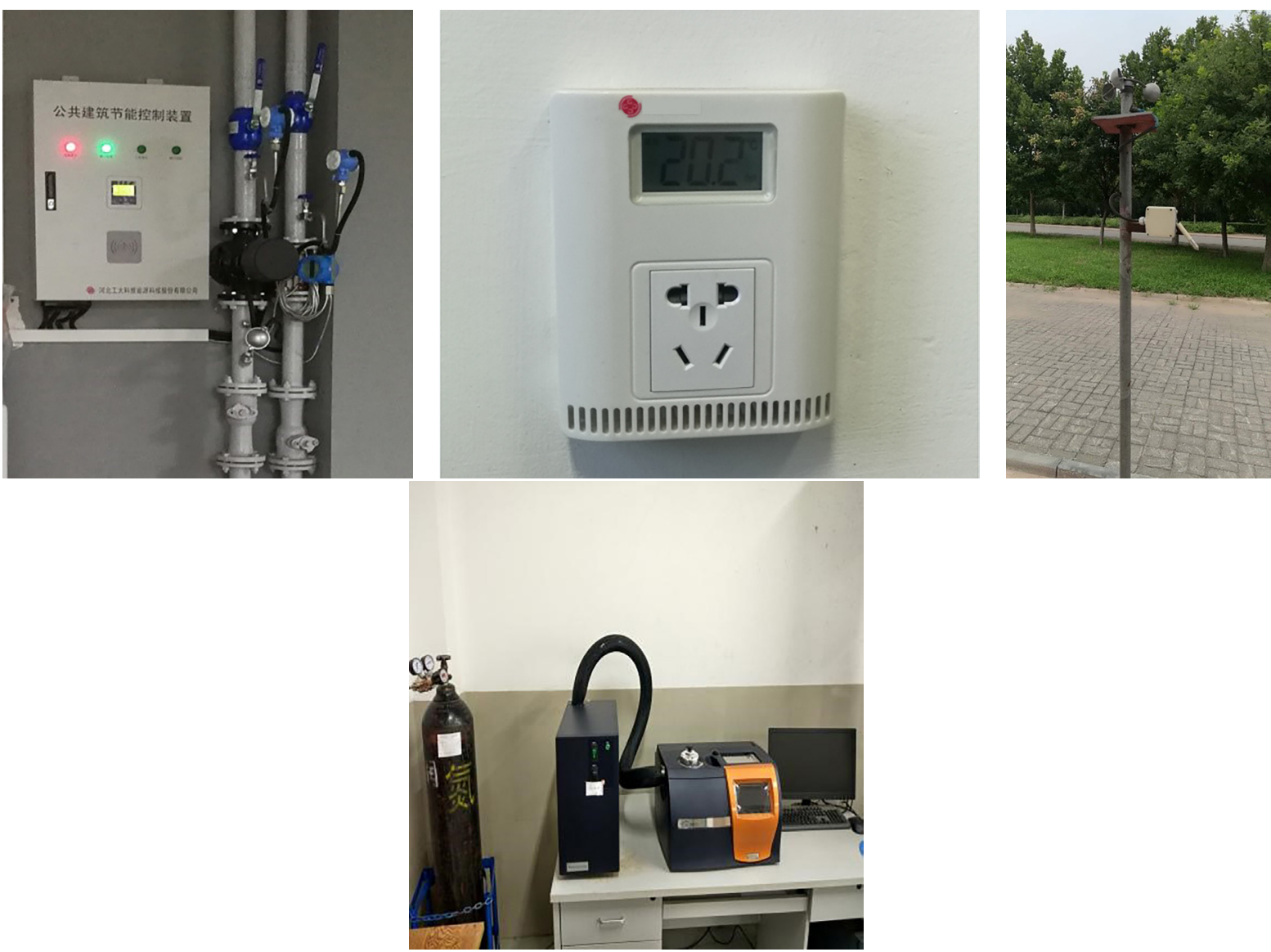

Figure 3: Photos of used devices

Table 1: Tested parameters and device specifications

\begin{tabular}{ccccc}
\hline $\begin{array}{c}\text { Serial } \\
\text { number }\end{array}$ & Tested parameters & Device name & Measuring range & Precision \\
\hline 1 & Supply and return water & Temperature sensor (PT100) & $-50 \sim 150^{\circ} \mathrm{C}$ & $\pm 0.1 \%$ \\
2 & Indoor temperature & Wireless temperature & $0 \sim 50^{\circ} \mathrm{C}$ & $\pm 0.2 \mathrm{~K}$ \\
& & monitoring device & & \\
3 & Outdoor temperature & Weather station & $-30 \sim 70^{\circ} \mathrm{C}$ & $\pm 0.2 \mathrm{~K}$ \\
4 & Specific heat capacity & $\begin{array}{c}\text { Differential scanning calorimeter } \\
5\end{array}$ & $-180 \sim 720^{\circ} \mathrm{C}$ & $\pm 0.01 \mathrm{~K}$ \\
\hline
\end{tabular}

hollow bricks, insulation material, external plastering and exterior wall paint. The thermophysical parameters of the room structure are shown in Table 2.

\section{Results and discussion}

Thermal mass model and thermal reserve coefficient model were used to analyze the thermal performance of the targeted building during a non-heating season and a heating season, respectively. In a non-heating season, the building thermal inertia was studied by analyzing delay rules between outdoor temperature and indoor temperature. In a heating season, the indoor temperature changes with increasing or decreasing the second supply water temperature. 


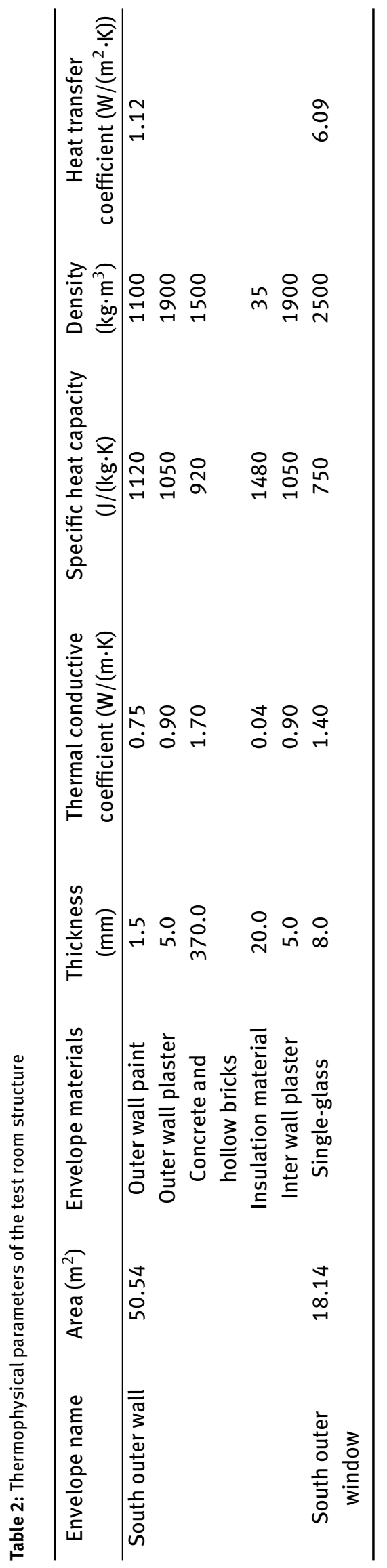


Table 3: Classification of building type

\begin{tabular}{ccccc}
\hline Serial number & Thermal mass & Attenuation & Delay & Building type \\
\hline 1 & $1 \leq K^{-1} \leq 10$ & Small & $1 \sim 3 \mathrm{~h}$ & Light \\
2 & $10 \leq K^{-1} \leq 35$ & Important & $>3 \mathrm{~h}$ & Comfortable \\
3 & $35 \leq K^{-1} \leq 100$ & Very effective & $+\infty$ & Heavy \\
\hline
\end{tabular}

\subsection{Thermal mass model}

Indoor temperature is considered as the evaluation index for indoor thermal comfort, without regard to thermal radiation, humidity and indoor ventilation. The change rule of the indoor temperature can be described by the first law of thermodynamics as follows:

$$
M C_{p} \frac{d t_{i}}{d \tau}=Q_{1}+Q_{2}+\ldots \ldots+Q_{n}
$$

where $M$ is the mass of the envelope, and $C_{P}$ is the constantpressure specific heat. $t_{i}, \tau$ and $Q$ represent indoor temperature, time of temperature change and inner heat source, respectively.

If the indoor temperature keeps stable or rising steadily due to a heat flux caused by one of inner heat sources, influence of other heat sources can be ignored. Then, Eq. (1) can be described as:

$$
\frac{d t_{i}}{d \tau}=\frac{U A}{M C_{p}}\left(t_{i}-t_{o}\right)
$$

where $U$ is heat transfer coefficient, and $A$ is heat transfer area. $t_{o}$ is outdoor temperature.

If $K$ is defined as the building thermal mass, then the Eq. (2) is introduced as:

$$
K=\frac{U A}{M C_{p}}=\frac{1}{\mathrm{n}} \sum_{j=1}^{n} \frac{U_{j} A_{j}}{M_{j} C_{j}}
$$

According to the results calculated by Eq. (3), building types are presented in Ref. [18]. The classification and building type are shown in Table 3. When delay time is between 1-3 hours, the building type can be classified as the light structure; as the delay time is more than 3 hours, the building type can be defined as the comfortable structure; when the delay time tends to be infinity, the building type can be considered as the heavy structure.

According to Table 2 and Eq. (3), the $K^{-1}$ is calculated as 4905 seconds, i.e., 1.36 hours. Therefore, the measured building type is classified as the light structure.

In order to validate the classification result of the targeted building type, an on-site thermal response test was conducted from 0:00 am on Oct 1th to 23:50 pm on Oct 5th in 2018. Outdoor temperature, wind speed and solar radiation were measured per minute. As shown in Figure 4,

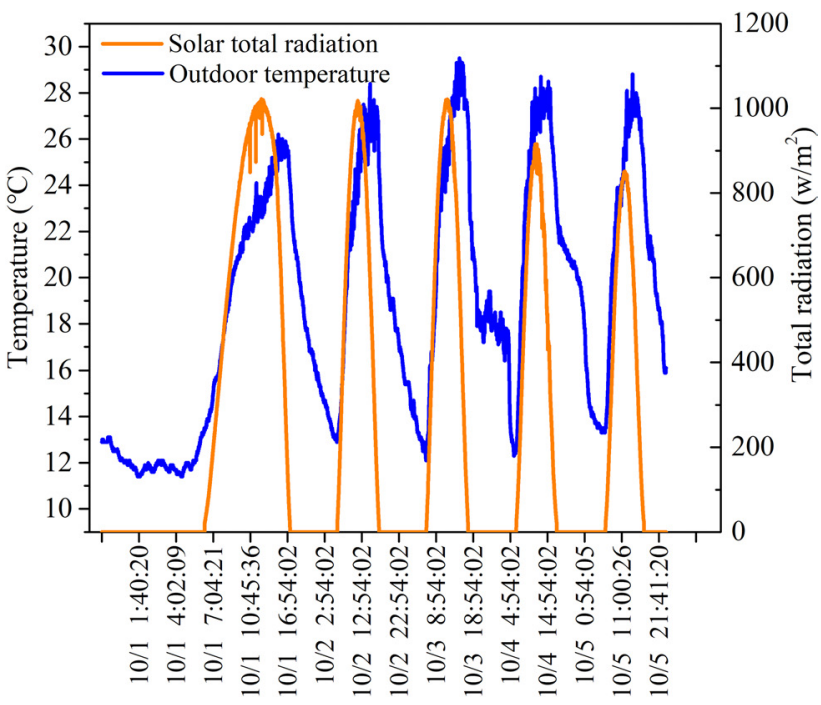

Figure 4: Curves of outdoor temperature and solar radiation

the peak value of the outdoor temperature was around $26-29^{\circ} \mathrm{C}$, which appeared between 14:50 pm and 15:20 pm every day. During the testing period, the minimum value of every day appears at 06:00 am, and the temperature changes from $12^{\circ} \mathrm{C}$ to $14^{\circ} \mathrm{C}$. Similarly, the change rule of solar total radiation was obvious, and the radiation value appears from 06:00 to 18:00 every day. The maximum solar total radiation was at 12:00 every day, and the instantaneous peak value was around $900-1000 \mathrm{~W} / \mathrm{m}^{2}$.

However, the change rule of the outdoor wind speed is inconspicuous. As shown in Figure 5, the maximum wind speed is nearly $9 \mathrm{~m} / \mathrm{s}$ on Oct 1 th, and the average daily wind speed is $4.1 \mathrm{~m} / \mathrm{s}$. From Oct 2 th to Oct 5 th, the variation trend of the wind speed is relatively steady, and the average value is about $2.7 \mathrm{~m} / \mathrm{s}$.

During the testing period, the change rules of solar radiation and outdoor temperature are similar. In order to analyze influence of the wind speed on the building thermal inertia, it is necessary to research the rule between the wind speed and the heat transfer coefficient of the outer wall surface.

Clarke model in Ref. [19] shows an empirical model between the outdoor wind speed and the heat transfer coeffi- 


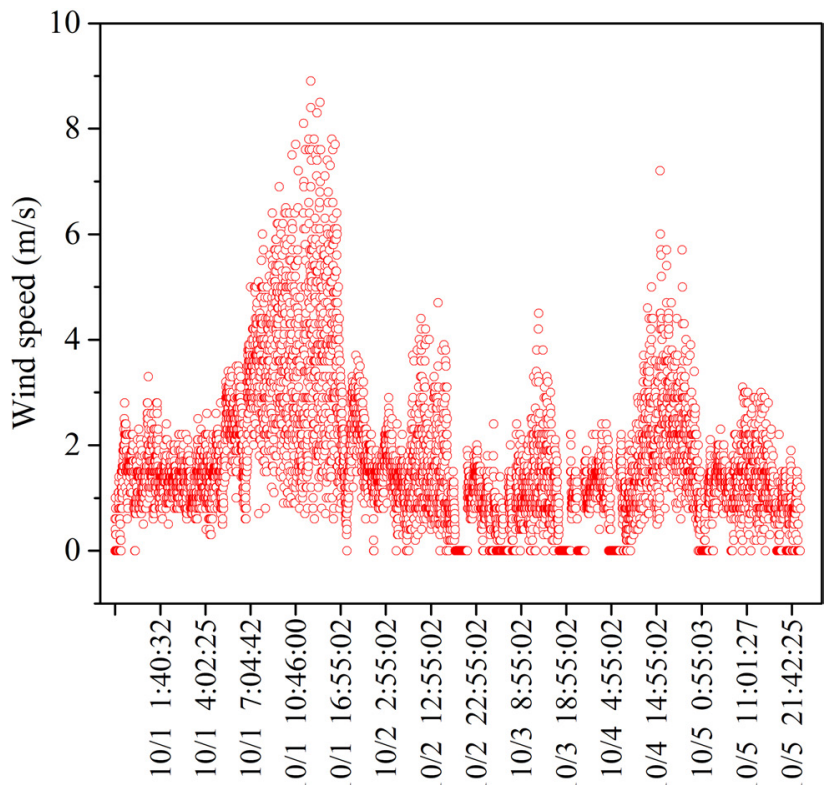

Figure 5: Outdoor wind speed

Table 4: Experimental constants of Clarke model

\begin{tabular}{cccc}
\hline Wind speed $(\mathrm{m} / \mathrm{s})$ & $a$ & $b$ & $c$ \\
\hline $0.00 \leq w \leq 4.88$ & 1.09 & 0.23 & 1.00 \\
$4.88 \leq w \leq 30.48$ & 0.00 & 0.53 & 0.78 \\
\hline
\end{tabular}

cient of the rough surface as follows:

$$
h_{w}=5.678\left[a+b\left(\frac{w}{0.304}\right)^{c}\right]
$$

where $h_{w}$ is heat transfer coefficient, and $w$ is wind speed. $a, b$, and $c$ are the experiment coefficients. These experiment constants are shown in Table 4.

Figure 6 shows the curves of the wind speed, the heat transfer coefficient of the outer wall surface, and integrated heat transfer coefficient of the outer wall. The heat transfer coefficient of the outer wall surface is direct ratio to the wind speed as shown in Figure 6.

When the wind speed increases from 4 to $5 \mathrm{~m} / \mathrm{s}$, the heat transfer coefficient of the outer wall surface has a step change from 23.37 to $38.61 \mathrm{~W} /\left(\mathrm{m}^{2} \cdot \mathrm{K}\right)$. Simultaneously, the integrated heat transfer coefficient of the outer wall increased from 2.89 to $3.18 \mathrm{~W} /\left(\mathrm{m}^{2} \cdot \mathrm{K}\right)$. As the wind speed exceeds $5 \mathrm{~m} / \mathrm{s}$, the integrated heat transfer coefficient is stable, and the final value is around $3.55 \mathrm{~W} /\left(\mathrm{m}^{2} \cdot \mathrm{K}\right)$. During the testing period, the range of the daily average wind speed is between 2.7 to $4.1 \mathrm{~m} / \mathrm{s}$, and the corresponding integrated heat transfer coefficient changes between 2.69 and $2.91 \mathrm{~W} /\left(\mathrm{m}^{2} \cdot \mathrm{K}\right)$. In this case, if the difference between indoor and outdoor temperatures is the same value, the fluctuation of the heat flow caused by the various wind

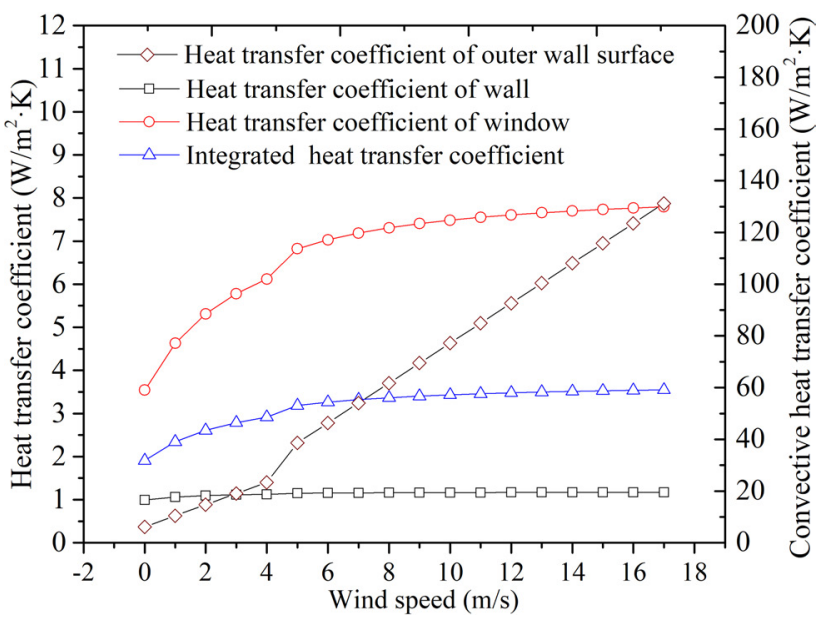

Figure 6: Relationships between the wind speed and the heat transfer coefficient

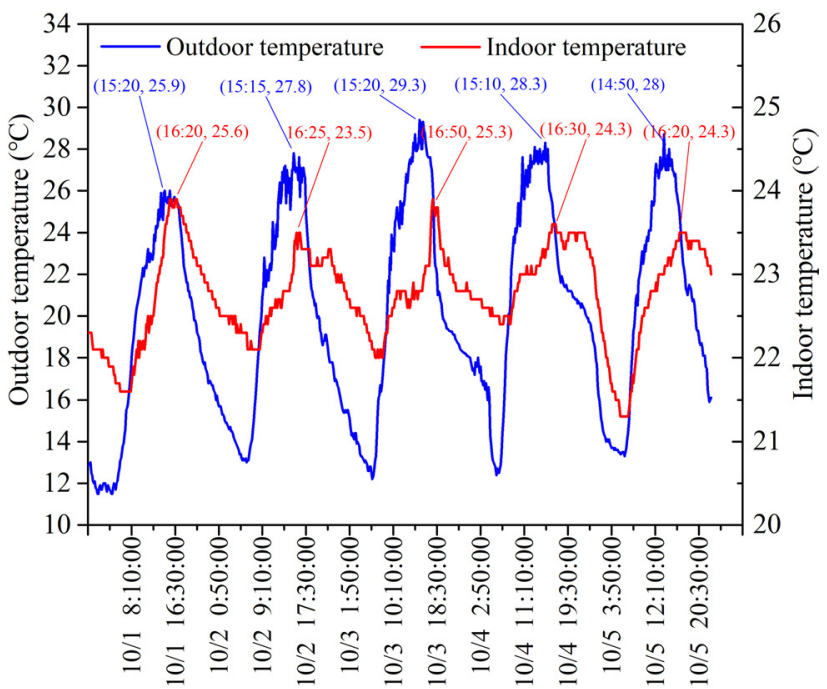

Figure 7: Delay rule between indoor and outdoor temperature

speed is within $8.18 \%$. In other words, influence of the wind speed for the wall integrated heat transfer coefficient can be ignored.

Figure 7 shows the delay and the attenuation rules between indoor temperature and outdoor temperatures. Measured data indicates that the peak value of the outdoor temperature appears between 14:50 and 15:20, and the maximum value changes from 26 to $29.3^{\circ} \mathrm{C}$. In addition, the peak value of the indoor temperature appears between 16:20 and 16:50, and the maximum value changes from 23.4 to $23.9^{\circ} \mathrm{C}$. The delay time caused by indoor and outdoor temperatures is around 1-1.5 hours. It can be seen from Figure 5, the wind speed on Oct 1th is obviously higher than those on other testing days. Although the fluctuation of the heat flow caused by the various wind speed is within $8.18 \%$, the delay time between the outdoor temper- 
Table 5: Monitoring parameters of different stages

\begin{tabular}{ccccc}
\hline Serial number & Time & $\begin{array}{c}\text { Change tendency of } \\
\text { indoor temperature }\end{array}$ & $\begin{array}{c}\text { Average indoor } \\
\text { temperature }\left({ }^{\circ} \mathrm{C}\right)\end{array}$ & $\begin{array}{c}\text { Average outdoor } \\
\text { temperature }\left({ }^{\circ} \mathrm{C}\right)\end{array}$ \\
\hline 1 & $18: 00-22: 00$ & stable & 17.73 & -5.42 \\
2 & $22: 00-00: 00$ & decreasing & 17.35 & -7.30 \\
3 & $00: 00-05: 00$ & stable & 16.33 & -8.20 \\
4 & $05: 00-10: 00$ & increasing & 16.32 & -8.91 \\
5 & $10: 00-12: 00$ & stable & 17.56 & -2.64 \\
\hline
\end{tabular}

ature and indoor temperature is different during the testing time. According to the classification of the building type as shown in Table 3, the temperature attenuation is small, and the delay time is short. In conclusion, the building type can be considered as the light structure. The overall envelope performance of the building needs to be improved in order to reduce the heat transfer coefficient of the outer windows, which can enhance the indoor thermal comfort.

\subsection{Thermal reserve coefficient model}

In heating season, the indoor temperature fluctuates with the outdoor temperature and the heat supply. As shown in Ref. [20], when the outdoor temperature and the supply water temperature change simultaneously, the change rule of the indoor temperature can be introduced as follows:

$$
Z=T \cdot \ln \frac{t_{i 0}-t_{0}-\beta\left(t^{\prime}{ }_{i}-t^{\prime}{ }_{0}\right)}{t_{i 1}-t_{0}-\beta\left(t^{\prime}{ }_{i}-t^{\prime}{ }_{0}\right)}
$$

where $Z$ is time of indoor temperature change from $t_{i 0}$ to $t_{i 1}$, and $t_{i 0}$ is steady indoor temperature before changing the supply water. $t_{i 1}$ is steady indoor temperature after changing the supply water, and $t_{o}$ is random outdoor temperature. $t_{i}^{\prime}$ is designed indoor temperature, and $t_{0}^{\prime}$ is designed outdoor temperature. $T$ is time constant, which represents required time as the indoor temperature changes from the initial value to the new steady value with the fastest rate. $\beta$ is limited heating coefficient, which is defined as a ratio of minimum needed heat load to the designed heat load at the designed outdoor temperature. Limited heating coefficient $\beta$ is described as:

$$
\beta=\left(t_{i 1}-t_{0}\right) /\left(t_{i}^{\prime}-t^{\prime}{ }_{0}\right)
$$

In this paper, the designed indoor and outdoor temperature are $18^{\circ} \mathrm{C}$ and $-7^{\circ} \mathrm{C}$, respectively. At a random outdoor temperature, the limited heating coefficient can be described as:

$$
\beta_{0}=\beta\left(t_{i}^{\prime}-t_{0}^{\prime}\right) /\left(t_{0}^{\prime}-t_{0}\right)
$$

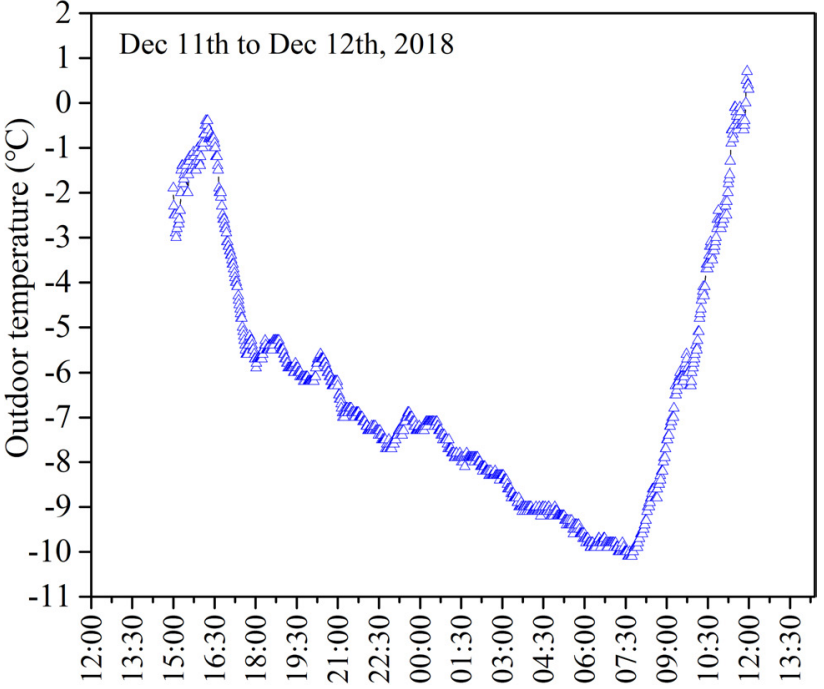

Figure 8: Curve of hourly outdoor temperature

If the Eq. (7) is introduced into Eq. (5), the Eq. (5) can be transformed as follows:

$$
Z=T \cdot \ln \frac{t_{i 0}-t_{0}-\beta_{0}\left(t^{\prime}{ }_{0}-t_{0}\right)}{t_{i 1}-t_{0}-\beta_{0}\left(t^{\prime}{ }_{0}-t_{0}\right)}
$$

Figures 8 and 9 show curves of outdoor temperature and indoor temperature with the changed water supply temperature from 15:00 pm on Dec 11th to 12:00 pm on Dec 12th, 2018, respectively. The second supply water temperature is adjusted by the electric valve on the primary side, which changes the flow rate of the primary supply water to meet the required temperature.

The experimental process is shown as follows: the second supply water temperature is decreased from $60^{\circ} \mathrm{C}$ to $55^{\circ} \mathrm{C}$ during 22:00 to 22:10 on Dec 11th, 2018. Then, the indoor temperature dropped from $17.9^{\circ} \mathrm{C}$ to $16.6^{\circ} \mathrm{C}$ during 22:30 pm on Dec 11th to 00:10 am on Dec 12th. Due to the reduction of the outdoor temperature, the indoor temperature also shows a slightly descending trend. The low temperature operation mode is finished at 5:00 am on Dec 12th, and the second supply water temperature is simultaneously increases to $60^{\circ} \mathrm{C}$. Finally, the room temperature 


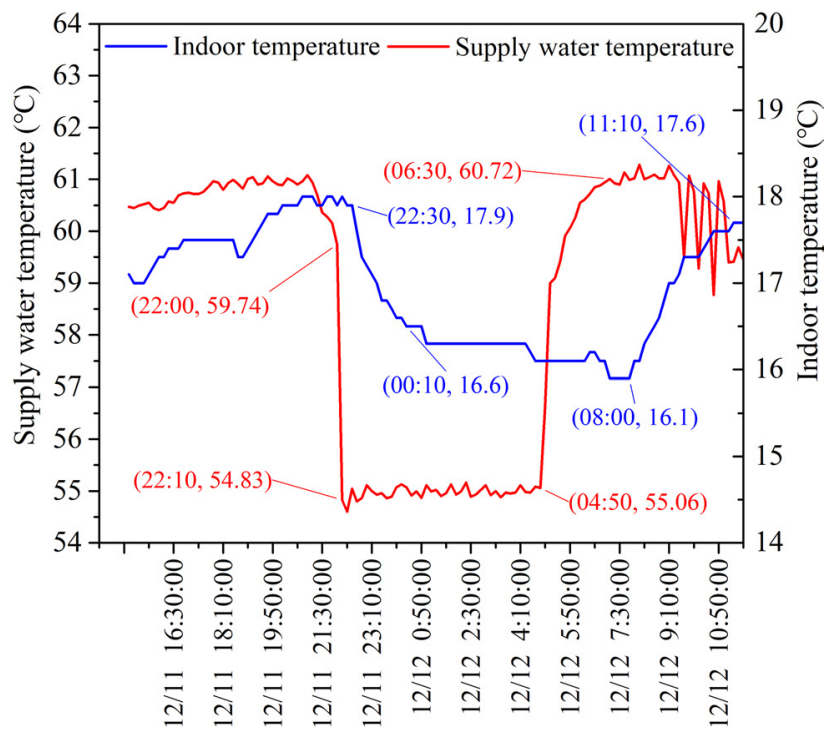

Figure 9: Curves of supply water and indoor temperature

raises slowly to around $17.6^{\circ} \mathrm{C}$ between 10:00 pm and 11:00 $\mathrm{pm}$ on Dec 12th, and its change trend is stable. With increasing and decreasing the second supply water temperature, the change ranges of the indoor temperature and the water supply temperature are $2^{\circ} \mathrm{C}$ and $5^{\circ} \mathrm{C}$, respectively.

The decreasing and increasing processes of the indoor temperature are about 2 hours and 5 hours, respectively. It is found that the increasing process is significantly slower than the decreasing process. The monitoring data of different stages are shown in Table 5.

Table 5 shows that the indoor temperature begins to drop at 22:00 pm on Dec 11th, and finally remained stable at 05:00 on Dec 12th. Some critical data during the testing process is analyzed as follows: the average outdoor temperature values are $-7.30^{\circ} \mathrm{C}$ and $-8.20^{\circ} \mathrm{C}$ during the decreasing stage and the stable stage, respectively. Therefore, the average outdoor temperature is $-7.75^{\circ} \mathrm{C}$ through the two stages. The average indoor temperature before the water supply temperature decreased is $17.73^{\circ} \mathrm{C}$. The steady average indoor temperature after the reduction of the water supply temperature is $16.33^{\circ} \mathrm{C}$. The limited heating coef ficient is 0.87 , and the decreasing time of the indoor temperature is 2 hours. By introducing these above values into Eq. (8), the thermal reserve coefficient is calculated as 35 hours. The thermal reserve coefficient is related to the heat flux of the envelope and the heat storage capacity of the room. Generally, the recommended value of the thermal reserve coefficient is between 40 and 70 hours.

As the thermal reserve coefficient in this article is less than the standard value, it is suggested that the thermal performance of the tested building should be improved.

\section{Conclusions}

A thermal response test was conducted for a public building, and two thermal performance evaluation models were adopted to estimate the thermal performance of the tested building. Evaluation results of these two models show the validity and the accuracy of the used methods. In a nonheating season, influence of weather factors on building thermal inertia was analyzed. In a heating season, the change rule of the indoor temperature was studied by raising and lowering the second supply water temperature. With the same testing conditions, the thermal response experiments are conducted repeatedly. In a non-heating season, the experimental results show that the delay time between the indoor temperature and the outdoor temperature is 1.1-1.5 hours, which is close to 1.36 hours from the calculation from the thermal mass model. The building type is classified as the light structure according to the research results. In a heating season, according to the thermal reserve coefficient model, the thermal reserve coefficient of the tested building is 35 hours, which is less than the recommend 40-70 hours. It is concluded that the building structure has poor thermal performance and heat storage capacity, which is consistent with the results by adopting the thermal mass model.

The two evaluation models of thermal performance are recommended for the buildings thermal response tests. The results will always hold regardless of weather, geographical site or operating conditions. Especially, the thermal reserve coefficient model can be considered as the priority option due to its simple experimental method and clear physical meaning. Therefore, the proposed two models are useful to analyze power savings in an energy supply system for a given building.

\section{References}

[1] Chel A., Kaushik G., Renewable energy technologies for sustainable development of energy efficient building, J. Alexandria Engineering Journal., 2018, 57(2), 655-699.

[2] Zhao X.L., Na L., Ma C.B., Residential energy consumption in urban China: A decomposition analysis, J. Energy Policy., 2012, 41, 644-653.

[3] Allouhi A., Fouih Y.E., Kousksou T., Jamil A., Zeraouli Y., Mourad Y., Energy consumption and efficiency in buildings: current status and future trends, J. Cleaner Production., 2015, 109, 118-30.

[4] Zhang Y.P., Lin K.P., Zhang Q.L., Di H.F., Ideal thermophysical properties for free-cooling (or heating) buildings with constant thermal physical property material, J. Energy and Buildings., 2006, 38(10), 1164-1170. 
[5] Wang J., Li G.L., Zhu H.X., Luo J., Sundén B., Experimental investigation on convective heat transfer of ferrofluids inside a pipe under various magnet orientations, J. International Journal of Heat and Mass Transfer., 2019, 132, 407-419.

[6] Gu J.H., Wang J., Qi C.Y., Min C.H., Sundén B., Medium-term heat load prediction for an existing residential building based on a wireless on-off control system, J. Energy., 2018, 152, 709-718.

[7] Gagliano A., Patania F., Nocera F., Signorello C., Assessment of the dynamic thermal performance of massive buildings, J. Energy and Buildings., 2014, 72, 361-370.

[8] Johra H., Heiselberg P., Dréau J.L., Influence of envelope, structural thermal mass and indoor content on the building heating energy flexibility, J., Energy and Buildings., 2019, 183, 325-339.

[9] Stazi F., Bonfigli C., Tomassoni E., Di P., Costanzo M., Placido., The effect of high thermal insulation on high thermal mass: Is the dynamic behavior of traditional envelopes in Mediterranean climates still possible, J. Energy and Buildings., 2015, 88, 367383.

[10] Sala J.M., Urresti A., Martín K., Flores I., Apaolaza A., Static and dynamic thermal characterization of a hollow brick wall: Tests and numerical analysis, J. Energy and Buildings., 2008, 40(8), 1513-1520.

[11] Desogus G., Mura Salvatore, Ricciu R., Comparing different approaches to in situ measurement of building components thermal resistance, J. Energy and Buildings, 2011, 43(10), 2613-2620.

[12] Aguilar F., Solano J.P., Vicente P.G., Transient modeling of highinertial thermal bridges in buildings using the equivalent thermal wall method, J. Applied Thermal Engineering, 2014, 67(1-2), 370377.
[13] Aste N., Leonforte F., Manfren M., Mazzon M., Thermal inertia and energy efficiency-Parametric simulation assessment on a calibrated case study, J. Applied Energy, 2015, 145, 111-123.

[14] Medjelekh D., Ulmet L., Abdou S., Dubois F., A field study of thermal and hygric inertia and its effects on indoor thermal comfort: Characterization of travertine stone envelope, J. Building and Environment, 2016, 106, 57-77.

[15] Gu J.H., Wang J., Qi C.Y., Yu X.J., Sundén B, Analysis of a hybrid control scheme in the district heating system with distributed variable speed pumps, J. Sustainable Cities and Society, 2019, 48.

[16] Liu X., The research on integrated thermal inertia of the lightweight building under the effect of multiple factors, D. Tianjin, Tianjin University, 2014.

[17] Han Y., Research on integrated thermal inertia of residential buildings in cold region of China, D. Tianjin, Tianjin University, 2011.

[18] Fernández J.L., Porta-Gándara M.A., Chargoy N, Rapid on-site evaluation of thermal comfort through heat capacity in buildings, J. Energy and Buildings, 2005, 37(12), 1205-1211.

[19] Clarke J.A., Energy simulation in building design, D. University of Strathclyde, Glasgow, Scotland: Adam Hilger Ltd, 1985.

[20] Zhan T.W., Zou P.H., Research on cooling process of heating rooms and intermittent (or limited) heating of heat networks, J. District Heating, 1995, 6, 13-19 